\title{
CARTOGRAFANDO O PANORAMA DA PESQUISA EM BIBLIOTERAPIA NO BRASIL: MAPA PRODUZIDO A PARTIR DO \\ TERRITÓRIO DA BASE REFERENCIAL DE ARTIGOS DE PERIÓDICOS EM CIÊNCIA DA INFORMAÇÃO (BRAPCI) E A PLATAFORMA LATTES
}

\author{
LUCAS VERAS DE ANDRADE ${ }^{* *}$ \\ ANA CAROLINE OLIVEIRA DA SILVA**
}

\begin{abstract}
RESUMO
O trabalho centra-se em apresentar o panorama da pesquisa em biblioterapia no Brasil. O corpus do estudo foi constituído a partir das informações contidas nos territórios da Base Referencial de Artigos de Periódicos em Ciência da Informação (BRAPCl) e na Plataforma Lattes, delimitando como recorte temporal os anos de 1975-2017. Nesse sentido, temos como objetivo geral: Mapear a produção científica brasileira em biblioterapia, tendo por base a BRAPCI. Elencam-se, ainda, como objetivos específicos: 1) Identificar o comportamento da produção em biblioterapia ao longo do tempo; 2) Levantar o perfil dos pesquisadores; 3) Mapear as instituições com grupos de pesquisa no tema ou linhas que tenham como escopo o estudo da biblioterapia e; 4) Demonstrar a área geográfica dos pesquisadores e os periódicos que mais publicam artigos relacionados ao tema. Para isso, utilizamos como metodologia a abordagem quanti-qualitativa com perspectiva descritiva, tendo, a partir da análise de conteúdo, a estruturação das categorias de análise. Os resultados demonstram que, apesar de um número considerável de pesquisadores, a pesquisa em biblioterapia demonstrase tímida quando comparada a outras áreas dentro do contexto da Biblioteconomia e da Ciência da Informação $(\mathrm{Cl})$, embora apresente crescimento constante ao longo dos anos. Nisso, destacamos dois grupos de Pesquisas: o Laboratório de Estudos em Biblioterapia, Bibliotecas Escolares e Leitura e o Grupo de Estudos e Pesquisas em Biblioteconomia e Ciência da Informação (GEPEBIC).
\end{abstract}

PALAVRAS-CHAVE: Biblioterapia. Pesquisa em Biblioterapia. Laboratório de Estudos em Biblioterapia, Bibliotecas Escolares e Leitura. Grupo de Estudos e Pesquisas em Biblioteconomia e Ciência da Informação. GEPEBIC.

\footnotetext{
* Estudo desenvolvido para o Grupo de Estudos e Pesquisas em Biblioteconomia e Ciência da Informação (GEPEBIC), da Universidade Estadual do Piauí (UESPI). Linha de Pesquisa: Literatura, Leitura e Biblioterapia.

** Professor das Séries Inicias da Educação Básica. Pesquisador vinculado ao Grupo de Estudos e Pesquisas em Biblioteconomia e Ciência da Informação (GEPEBIC), do Centro de Ciências Sociais Aplicadas, da Universidade Estadual do Piauí - UESPI.

${ }^{* * *}$ Graduada em Biblioteconomia na Universidade Estadual do Piauí - UESPI.
} 


\begin{abstract}
The paper focuses on presenting the panorama of research in bibliotherapy in Brazil. The corpus of the study was constituted from the information contained in the territories of the Reference Database of Periodical Articles in Information Science (BRAPCI) and the Lattes Platform, delimiting as a temporal cut the years 1975-2017. In this sense, we have as general objective: Mapping Brazilian scientific production in bibliotherapy, based on BRAPCl. Also listing specific objectives: 1) Identify the behavior of production in bibliotherapy over time; 2) Raise the profile of the researchers; 3) Map the institutions with research groups on the theme or lines that has as scope the study of bibliotherapy and; 4) Demonstrate the geographical area of researchers and journals that publish articles related to the topic. For this, we use as methodology, the quantitative-qualitative approach with a descriptive perspective, having from the analysis of content the structuring of the categories of analysis. The results show that despite a considerable number of researchers, the research in bibliotherapy is shown to be timid when compared to other areas within the context of Librarianship and Information Science $(\mathrm{Cl})$. However, steadily growing over the years. In this, we highlight two research groups: the Laboratory of Studies in Biblio-therapy, School Libraries and Reading and the Group of Studies and Research in Librarianship and Information Science (GEPEBIC).
\end{abstract}

KEYWORDS: Bibliotherapy. Research on Bibliotherapy. Laboratory of Studies in Bibliotherapy, School Libraries and Reading. Group of Studies and Researches in Librarianship and Information Science. GEPEBIC.

\title{
1 INTRODUÇÃO
}

Antes de adentrarmos nos meandros que propomos refletir, salientamos que a ideia de cartografia admitida no estudo parte da metáfora de escavação arqueológica de dispositivos, compreensão desenvolvida por Foucault (2000). Nesse sentido, cartografar está estritamente relacionada a uma abordagem territorial explícita. No caso da produção de pesquisas acadêmicas, segue o raciocínio de rastrear o território de bases de dados, escavar sistematicamente esses espaços para identificar, descrever e interpretar informações que nelas se encontram armazenadas acerca de um tema.

Por esse ângulo, temos como espectro a pesquisa em biblioterapia. Trata-se de uma linha de estudo e atuação dentro da área de Biblioteconomia que tem por objetivo a reflexão das narrativas biblioterapêuticas (ANDRADE, 2018). O seu foco é o autoconhecimento (interpretação/reinterpretação) dos indivíduos, mediado por um aplicador (um bibliotecário, psicólogo ou profissional que tenha como objeto da profissão a humanização e 
bem-estar dos indivíduos). Para isso, tem-se a utilização da literatura, a verbalização ou/e outra linguagem (música, escultura, pintura, entre outras) em conexão com seis princípios: catarse, humor, identificação, projeção, introjeção e introspecção.

Apesar de termos uma noção conceitual bem desenvolvida e alguns estudos que a demonstram sob uma epistemologia que a consolida como tema e objeto para a ciência (OUAKNIN, 1996; CALDIN. 2010) ${ }^{1}$, a área, enquanto campo de investigação, principalmente quando se refere ao espaço geográfico de Brasil, encontra-se ainda em estágio de afirmação. Embora ela já seja uma senhora centenária, com uma longa história, como sugere (SILVA, 2005). Nisso, é interessante demonstrar o comportamento da produção no tema e a regularidade dela. É com base nessa perspectiva que descortinamos a problemática do estudo: Qual o panorama da pesquisa em biblioterapia no Brasil?.

Diante dela, elegemos como objetivo geral: Mapear a produção científica brasileira em biblioterapia, tendo como diretriz a Base Referencial de Artigos de Periódicos em Ciência da Informação (BRAPCl). Estabelecendo ainda, como objetivos específicos: 1) Identificar o comportamento da produção em biblioterapia ao longo do tempo; 2) Levantar o perfil dos pesquisadores; 3) Mapear as instituições com grupos de pesquisa no tema ou linhas que têm como escopo o estudo da biblioterapia e; 4) Demonstrar a área geográfica de atuação dos pesquisadores e os periódicos que mais publicam artigos relacionados ao tema. Com a evidência desses objetivos, compreendemos que, à medida que haja a geração de informações sobre o tema, a análise, compreensão e disseminação dessas informações, estas podem impulsionar o avanço científico na área. Contribuindo, inclusive, para a identificação de tópicos ainda não cobertos por estudos ou mesmo para a apresentação de temas que, inseridos no escopo de investigação, ainda se encontram desconhecidos pela comunidade acadêmica. Isso pode potencializar o desenvolvimento de estudos que viabilizem mais ainda os benefícios para aqueles que se utilizam da prática em biblioterapia.

$O$ interesse no estudo se inscreve sob duas perspectivas. Embora os autores da escrita deste trabalho tenham a biblioterapia como temática de pesquisa, o primeiro autor, segundo a ordem de apresentação de autoria, é pesquisador do Grupo de Estudos e Pesquisas em Biblioteconomia e Ciência da Informação (GEPEBIC), da Universidade Estadual do Piauí (UESPI). No momento, busca analisar

\footnotetext{
${ }^{1}$ Maiores referências e autores mais conhecidos no tema em âmbito de Brasil.
} 
grupos de pesquisas e pesquisadores da temática, de modo, a estabelecer diálogo de colaboração, uma vez que, dos integrantes do grupo GEPEBIC, é o único que problematiza especificamente o tema. Por essa ótica, intenciona-se a criação de uma rede de colaboração entre pesquisadores e grupos de pesquisas com a finalidade de reflexão de textos e de colaboração na produção de trabalhos.

Já pela segunda perspectiva, tem-se a outra pesquisadora que se encontrava, no momento da produção deste estudo, no período de escrita monográfica sobre 0 tema. Nessa circunstância, 0 entendimento, o conhecimento e a compreensão de muitos dos aspectos elencados nos objetivos desta escrita deram a ela condições na produção do estado da questão ${ }^{2}$ sobre a temática biblioterapia. Aspecto que contribui para o pesquisador, no intuito de levá-lo "a registrar, a partir de um rigoroso levantamento bibliográfico, como se encontra o tema ou o objeto de sua investigação no estado atual da ciência ao seu alcance" (NÓBREGA-THERRIEN; THERRIEN, 2004, p. 7). Desse modo, este aspecto contribuiu para a delimitação do que estudar no contexto da biblioterapia.

Assim, a pesquisa se torna relevante uma vez que demonstra o panorama e a produção de conhecimento acerca da biblioterapia na literatura periódica em Ciência da Informação $(\mathrm{Cl})$ e Biblioteconomia no Brasil. Condição esta imprescindível para a problematização desta linha de saber, no sentido de potencializar caminhos para o aprimoramento e compreensão intelectual que orienta as práticas empíricas e científicas dos estudos sobre a temática.

Apesar de os saberes contidos nos periódicos serem apenas um recorte, dentro do espaço cartográfico que contém informações sobre o tema aqui em foco, nossa escolha e limitação neles apresenta-se na argumentação de Cunha (2001), que entende serem eles "um dos mais eficientes meios de registro e divulgação de pesquisas, estudos originais e outros tipos de trabalho intelectual" (CUNHA, 2001, p. 16-17). Portanto, é fonte basilar para pesquisadores que buscam o entendimento de continuum ${ }^{3}$ e atualização de determinado tema.

Dessa forma, o estudo se apresenta em tópicos, sendo que, no primeiro, temos a introdução. Nela, expressamos uma noção breve sobre a temática $e$ as nossas motivações para o

2 Trata-se da delimitação do problema específico de pesquisa. Ver (NÓBREGATHERRIEN; THERRIEN, 2004, p. 7).

3 Palavra derivada do latim, que pode ser traduzida literalmente como "contínuo", continuidade. 
desenvolvimento do estudo. Em seguida, damos um entendimento sobre o periódico, enfocando o periódico eletrônico acadêmico e a Base Referencial de Artigos de Periódicos em Ciência da Informação (BRAPCI), como o universo de publicações científicas em Ciência da Informação $(\mathrm{Cl})$ e Biblioteconomia no Brasil. Logo após, trazemos um tópico referente à biblioterapia, no qual apresentamos o conceito, os princípios e as tipologias. No quarto, demonstramos as rotas seguidas no intuito cartográfico que percorremos. Temos, ainda, as análises e, por fim, a configuração final do mapa, onde apontamos algumas considerações e retomamos os principais contornos desenhados no percurso de nosso estudo.

\section{PERIÓDICO CIENTÍFICO E A BRAPCI COMO O UNIVERSO DE PERIÓDICOS EM CI E BIBLIOTECONOMIA NO BRASIL}

A compreensão que defendemos sobre periódico científico é de uma revista científica. O objetivo é a divulgação de estudos e dados a respeito de determinados temas, após uma análise crítica e validação científica, com a finalidade de potencializar o progresso da ciência. No entanto, apontamos que, além da terminologia e concepção de periódico como revista científica, outras nomenclaturas como publicação seriada e revista técnica somam-se no intuito de designar essa tipologia de documento.

Nesse sentido, o primeiro periódico de cunho científico de conhecimento da academia é o Journal de Sçavans (MUELLER, 2000), publicado em Paris em 1665. Ele teve como fundador o frânces Denis de Sallo, que estabeleceu como objetivo a catalogação e a divulgação de informações sobre a bibliografia da época publicada na Europa, além de resumir, demonstrar, explicar e descrever experiências em física, química, anatomia, invenções curiosas, meteorologia e aspectos dignos da curiosidade humana. Ele teve suas publicações descontinuadas por várias vezes em represália da corte francesa Muller (2000 apud MCKIE, 1948; HOUGHTON, 1975).

Meses após o surgimento do Journal de Sçavans, surgiu, em Londres, amparado por um grupo de filósofos ingleses ligados à Royal Society, o segundo periódico, o Philosophical Transacional of the Royal Society of London (SOUZA; ALBUQUERQUE, 2005). Igual ao Journal de Sçavans, o Philosophical Transacional of the Royal Society of London continha os mesmos objetivos no entanto, diferenciou-se à medida que tinha, também, a "intenção de divulgar, entre os membros da Royal Society, [...] cartas enviadas por [...] 
colegas cientistas (ingleses e europeus) relatando suas pesquisas" (MULLER, 2000, p. 75).

Além da noção que defendemos e o objetivo compreendido a partir dos precursores desta tipologia de divulgação e disseminação científica, o periódico científico, possui outras funcionalidades. Assim, ele registra e preserva o conhecimento científico, garante ao pesquisador a autoria e, por consequência, a propriedade intelectual do registro. Por fim, garante, ainda, uma qualidade sobre a produção científica, já que, para um manuscrito ser validado cientificamente, ele passa por um crivo de especialistas que conferem a ele autoridade na temática da escrita.

Apesar de ainda encontrarmos periódicos científicos na versão tradicional (impressos), atualmente, é mais comum o formato eletrônico devido a uma série de aspectos que tornam inviável a permanência deles enquanto veículo de divulgação científica. Entre eles, a proliferação de periódicos ocasionados em função do avanço da ciência e do aumento do número de pesquisas e pesquisadores que, propositalmente, é provocado pelas instituições acadêmicas e de fomento à pesquisa, já que a progressão de um pesquisador vinculado a elas, principalmente quando públicas, está atrelada ao produtivismo. Isso faz com que os investigadores se esforcem na produção em larga escala enquanto estiverem ativos na posição de cientistas e vinculados a elas.

Isso implica "[...] na proliferação de [profissionais] focados [e] [...] valorizados em suas respectivas áreas de atuação por critérios meramente quantitativos" (VOSGERAU; ORLANDO; MEYER, 2017, p. 234). O aspecto que mais contribui para a tendência eletrônica é o custo de manutenção das coleções. Nessa perspectiva, além de contar com a agilidade nas publicações, aspecto negativo na versão impressa, a versão eletrônica barateia a gerência e conservação das coleções. Nisso, Muller (2000, p. 82) apresenta o seguinte conceito sobre a versão eletrônica do periódico:

A expressão periódicos eletrônicos, designa periódicos aos quais se tem acesso mediante o uso de equipamentos eletrônicos. Podem ser classificados em pelo menos duas categorias, de acordo com o formato em que são divulgados: online e em CD-ROM.

O periódico, enquanto categorias, versão on line e Cd-rom, diferencia-se. Enquanto a primeira se estabelece disponível a partir da Internet; a segunda pode ser analisada a partir de um microcomputador, de forma isolada, estando ele conectado ou não 
com a Internet. Considerando o escopo do estudo e trazendo essa discussão para o âmbito de Brasil, Ohira; Sombrio; Prado (2000) apontam como a primeira revista científica nacional a Memórias do Instituto Osvaldo Cruz, sendo publicada por volta de 1910. E especificando ao contexto da Ciência da Informação a divulgação científica por meio de periódicos, começou a surgir, na década de 70, do século passado (MENDONÇA, 2016).

Nisso, tem-se como mola propulsora o desenvolvimento no país de cursos em nível de pós-graduação em Ciência da Informação, que possibilitou a emergência de uma literatura na área $e$, por consequência, o surgimento de periódicos científicos, sendo a Revista da Escola de Biblioteconomia da UFMG (atualmente com a nomenclatura, Perspectivas em Ciência da Informação) e Ciência da Informação, a partir de 1972, as precursoras da divulgação científica por meio desse veículo de comunicação da informação, em Ciência da Informação, em nosso país.

De 1972 até o contexto atual, a área de $\mathrm{Cl}$ e Biblioteconomia conta com um quantitativo de (53) cinquenta e três periódicos, estando vigentes, em âmbito de Brasil, atualmente, (41) quarenta e um. Nessa perspectiva, tendo por base a temática de nosso estudo, rastrear a produção em biblioterapia e o aumento de periódicos sob o viés de uma temática específica implica, diretamente, a dispersão de artigos em uma multiplicidade de títulos.

Nesse sentido, é interessante identificar os periódicos que têm como escopo o assunto. Por essa ótica, entra em cena a Base de dados Referencial de Artigos de Periódicos em Ciência da Informação (BRAPCI), que, segundo Freitas; Nascimento; Bufrem (2014) é a base mais completa, em forma de repositório, relacionada à produção de periódicos científicos dentro da $(\mathrm{Cl})$ no Brasil. Ela é fruto de um projeto de pesquisa que tem como título Opções metodológicas em pesquisa: a contribuição da área da informação para a produção de saberes no ensino superior. Mantida pelo Grupo de Pesquisa Educação, Pesquisa e Perfil Profissional em Informação (E3PI), da Universidade Federal do Paraná (UFPR) e financiada pela Conselho Nacional de Desenvolvimento Científico e Tecnológico (CNPq) (AMORIM NETO; LIMA, 2016).

Desse modo, ela informa e divulga pesquisas existentes em sua estrutura. Assim, é de extrema importância para área da $(\mathrm{Cl})$, já que coopera com a pesquisa e pesquisadores no sentido de descortinar as tendências nas pesquisas e o movimento epistemológico da produção de determinadas temáticas dentro do escopo da $\mathrm{Cl}$ e Biblioteconomia. 
Ela é composta por todos os periódicos vigentes da área, cobrindo, ainda, os que se apresentam em descontinuidade, em um total de (12) doze, considerados históricos, a citar: Arquivo \& Administração (1972-1998); Cadernos de Biblioteconomia (19731989); Estudos Avançados em Biblioteconomia e Ciência da Informação (1982-1986); Infociência (1997-2004); Informare (19952000); Revista da Escola de Biblioteconomia da UFMG (1972-1995); Revista de Biblioteconomia \& Comunicação (1986-2000); Revista de Biblioteconomia de Brasília (1973-2001); Revista do Departamento de Biblioteconomia e História (1978-1983); Revista Online da Biblioteca Prof. Joel Martins (1999-2001) e Revista Latino-americana de Documentacion (1981-1983); Arquivística.net (2005-2008) e DataGramaZero (1999-2015).

Cabe, ainda, ressaltar que ela, no contexto atual ${ }^{4}$, possui, em seu acervo, a indexação de 16.826 (dezesseis mil e oitocentos e vinte e seis) trabalhos em revistas científicas, possuindo, com isso, um total de 13.585 (Treze mil, quinhentos e oitenta e cinco) autores. A seguir, algumas noções para o entendimento do tema biblioterapia.

\section{BIBLIOTERAPIA: O QUE É?}

A palavra biblioterapia é um substantivo feminino formado pela união de dois elementos de origem grega: biblíon (livro) e therapieia (terapia), que significa tratamento ou restabelecimento da saúde. Consequentemente, pela junção etimológica dos dois termos, apreende-se como significação terapia por meio de livros.

Observamos que a ideia de apropriação da biblioterapia, no que compete ao campo da Biblioteconomia, é recente se comparada a sua história. Ao analisarmos esta última, identificamos que, desde a idade média, podem ser encontrados relatos da prática do uso da leitura com intuito terapêutico. Nesse intento, primeiramente, temos os gregos, "suas bibliotecas eram consideradas repositórios de remédio para o espírito" (PEREIRA, 1996, p. 36).

Em seguida, no Egito antigo, temos a figura do Faraó Ramsés II, que possuía, em sua biblioteca, um frontispício com a frase: Remédio para alma (SEITZ, 2005). Essa proposição também é observada na Suíça, na Abadia de São Gall (uma biblioteca pública de empréstimo, que possuía, em sua coleção, livros e manuscritos - textos irlandeses, antigas bíblias em alemão e poesias de monges). Nela, localizava-se a inscrição "Tesouro de remédio da alma" (PEREIRA, 1996, p. 36), em

${ }^{4}$ Fonte: http://www.brapci.inf.br/index.php. 
que textos sagrados eram recitados. Isso demonstra que a leitura com função terapêutica data de muito tempo.

No entanto, esses registros demonstram, a nosso ver, apenas a leitura sob o viés da concepção de terapia. A prática da biblioterapia mediada emerge em si, ao final do século XVIII, quando os livros começaram a ser usados no tratamento de doentes mentais na França, Inglaterra e Itália (LEITE, 2009). Nesse contexto, começavam a aparecer os primeiros feitos com a biblioterapia através do médico Benjamim Rush, primeiro médico a recomendar a leitura em hospitais como parte de tratamento para diversos doentes. Já em 1853, o médico Jhon Minson Galt II escreve o primeiro artigo que relata os benefícios terapêuticos por meio da literatura no tratamento de doentes mentais (ALVES, 1982). No entanto, só por volta de 1916 o termo biblioterapia apareceu de forma conceitual, tendo sido "pensado por Samuel Mchord Crothers, em artigo publicado no Atlantic Monthy" (PINTO, 2005, p. 39, grifo nosso).

No entanto, as precursoras em analisar a biblioterapia em profundidade de forma científica foram Caroline Shordes e Esther J. Junior, em meados de 1949, a partir da pós-graduação em nível de doutorado. Enquanto a primeira identificou duas tipologias literárias úteis à biblioterapia: a didática e a literatura imaginativa; a segunda analisou aspectos médicos da literatura, atrelando noções de filosofia, psicologia e ciência biblioteconômica (ORSINI, 1982).

De lá até o contexto atual, a biblioterapia vem buscando conquistar espaço e procurando se firmar como área de conhecimento, demonstrando que é um campo de atuação para profissionais diversos. Com isso, são vários os autores que se debruçam em conceituá-la e a noção que admitimos é de Caldin (2001; 2002; 2003; 2010) por ser ela a autora mais influente na área no Brasil.

Dessa forma, ela a conceitua como uma leitura dirigida e discussão em grupo que agrega a interatividade entre as pessoas, levando cada um a expor seus sentimentos. Por esse entendimento, a leitura e o diálogo são o convite para a integração entre as pessoas e o texto. É nessa relação que acontece o contato do leitor com o que ele almeja encontrar através da biblioterapia, ou seja, os sentimentos fluem em meio à essa interação. Todo esse processo não ocorre simplesmente pela leitura de um texto, por trás de todo esse contexto, existe planejamento e análise da realidade de cada participante ou leitor, mediado por um aplicador.

Cabe destacar que a biblioterapia não se limita à literatura. Como já exposto, ela pode, em uma intervenção, ser auxiliada pela música, a pintura entre outros aspectos que possibilitem a 
"emergência da subjetividade" (ANDRADE; VIANA, 2017, p. 164). No entanto, a literatura é o caminho mais utilizado.

De acordo com Valencia; Magalhães (2015, p. 15), "a literatura serve de maneira lúdica, como fonte de reflexão, aprendizado e lazer, aliada a finalidade de trazer conforto e ajudar as pessoas em situações críticas". Nesse sentido, ao ler ou ouvir um texto previamente selecionado, o leitor ou ouvinte identifica-se com as ações de um personagem ou enredo, de modo a relacionar-se com uma situação já vivenciada.

Desse modo, a leitura vai além do que está escrito, aspecto essencial nas intervenções biblioterapêuticas e que se demonstra através de um processo subjetivo mediante princípios: a catarse, o humor, a identificação, a introjeção, a projeção e a introspecção, como já apontado. Catarse é um conceito desenvolvido pela psicanálise e objetiva a eliminação das perturbações psíquicas, tensões, angústias pelo viés do lado emocional.

Caldin (2001) enfatiza que a catarse, como componente biblioterapêutico, processa-se da mesma forma que um bom estado de espírito (tranquilidade). Com isso, compreendemos que a catarse, na biblioterapia, é um princípio que gera equilíbrio e alívio de tensões, sendo que o texto pode provocar ou modificar emoções na pessoa que está lendo. Assim sendo, o consideramos como instrumento essencial para o tratamento do espírito.

O princípio do Humor tem como finalidade transformar uma tristeza em alegria. Por meio da leitura, podemos identificar as sensações, e, nisso, possuímos a capacidade de transformar a dor em prazer. Textos que carregam consigo o humor transportam uma liberdade diante das emoções, transfigurando-as. Por essa perspectiva, a dor é esquecida em detrimento do prazer. Já a identificação, Caldin (2001, p. 38) afirma que é "um fator importante no que tange ao desenvolvimento da personalidade do indivíduo", ela nos acompanha desde a infância. Quando crianças, identificamo-nos com nossos pais, com as pessoas que admiramos e até com animais. Nesse sentido, o princípio da identificação pode ser entendido como enxergar em um objeto ou algo uma resposta às nossas necessidades. Na biblioterapia, seria ver-se diante de um reflexo mediante a leitura.

Ao que compete a introjeção, relaciona-se ao processo psicológico de a pessoa assimilar uma propriedade, um aspecto ou uma característica do outro e levar para si, para, posteriormente, transformar-se total ou parcialmente nessas características. Esse princípio está ligado à identificação. A projeção, como o próprio 
nome já indica, é o ato de projetar ao/no outro nossas ideias. Nesse processo, ocorre a transferência de sentimentos, expectativas, desejos, sonhos e intenções. Por fim, a introspecção, que se configura em uma análise interior processo quando a pessoa aplica na sua vida o que foi lido e interpretado através da reflexão da leitura, podendo ser uma ferramenta passível de mudanças comportamentais. Portanto, é a partir desse conjunto de princípios ou componentes biblioterapêuticos que ocorre a biblioterapia. Cabe, ainda, apontar que ela é desenvolvida mediante três tipologias de práticas: a Biblioterapia Clínica, a Biblioterapia Institucional e a Biblioterapia de Desenvolvimento Pessoal.

$\mathrm{Na}$ primeira, o processo geralmente acontece mediante um diagnóstico, o que não impede que também nessa área se desenvolvam atividades sem vínculo patológico. Possui como foco pessoas com problemas de saúde mental ou com distúrbios de comportamento. Utiliza-se de atividades bem estruturadas que visam ao auxílio de grupo ou pessoas, individualmente, com propósitos de saúde. Geralmente, nessa tipologia, o aplicador da técnica é um profissional da área da saúde, a exemplo, médicos.

Já na biblioterapia Institucional, o objetivo é a formação dos indivíduos, de modo a impulsionar mudanças comportamentais aos colaboradores de uma empresa e/ou instituições em geral, com vistas a potencializar, com eficiência e eficácia, a efetivação de metas e resultados previstos a partir de um planejamento. Está relacionada ao uso da literatura com pessoas de uma instituição, individual ou coletivamente. Nela, tanto os bibliotecários como profissionais vinculados a essas instituições, desde que tenham conhecimento da biblioterapia, podem aplicá-la.

Por fim, a Biblioterapia de Desenvolvimento, cujo sentido é habilitar os indivíduos em suas potencialidades, buscar que os sujeitos se reconheçam em seu potencial máximo. Desse modo, utiliza-se da leitura imaginativa para o tratamento, sendo realizada em grupo ou não, podendo ter como liderança na aplicação o profissional bibliotecário. Possui como uma de suas metas ajudar as pessoas a realizarem tarefas comuns e suportarem problemas diários.

A partir das explicações acima, percebemos características e distinções entre as tipologias da biblioterapia, que vão desde o seu formato às suas metas. No entanto, as três apresentam um objetivo único: trabalhar pontos que se fazem importantes na vida de um e/ou vários indivíduos. A seguir, o delineamento metodológico do estudo.

4 A CONSTRUÇÃO METODOLÓGICA DO ESTUDO: A BRAPCI E A 


\section{PLATAFORMA LATTES COMO PAISAGEM DE RASTREIO}

A pesquisa foi desenvolvida na perspectiva descritiva com abordagem quanti-qualitativa, associada à análise de conteúdo de Bardin (2009). Nesse sentido, entendemos por pesquisa descritiva aquela que tem por objetivo a descrição de uma determinada realidade. Para isso, exige do "pesquisador [o levantamento de] uma série de informações sobre o que deseja pesquisar" (GERHARDT; SILVEIRA, 2009, p. 35).

Já em relação à abordagem quanti-qualitativa, a compreensão dada é o diálogo entre duas abordagens no modo de fazer pesquisa. Enquanto a primeira recorre à estatística na explicação dos dados; a abordagem qualitativa lida com a interpretação de uma realidade social (SOUZA; KERBAUY, 2017). A parte qualitativa emerge quando nós pesquisadores produzimos inferências aos aspectos quantitativos cartografados, produzindo, assim, significações sobre estes e dialogando, ainda, quando possível, com a fala de autores.

Nesse sentido, para a coleta de dados, tivemos, como território, a base de dados em Ciência da Informação (BRAPCl) e a Plataforma Lattes. A escolha da BRAPCI deu-se por ser ela, como já evidenciado, um meio que disponibiliza e colabora com estudos analíticos e descritivos sobre a produção editorial de uma área científica (aqui tendo como escopo a biblioterapia no contexto da $\mathrm{Cl}$ ), além de listar e conter, em seu interior, todos os periódicos vigentes da área foco do estudo. Outro aspecto que ratifica nossa escolha é ela disponibilizar textos completos e o acesso irrestrito a eles.

Desse modo, definimos como descritor de busca apenas o termo biblioterapia. Cabe esclarecer que, além dele, também fizemos buscas a partir do descritor leitura lúdica, termo também presente nas práticas e denominações da biblioterapia. No entanto, foi desconsiderado, já que, com esse, alguns dos trabalhos levantados não se relacionavam com o tema (10 trabalhos) e os que estabeleciam ligação (4 trabalhos) também foram encontrados com a busca a partir do termo biblioterapia.

Nessa perspectiva, na busca foram recuperados 49 (quarenta e nove) documentos, entre artigos de periódicos acadêmicos (47), trabalhos apresentados em eventos (1) e editoriais (1). Como o recorte definido para o estudo foi o artigo publicado em periódico acadêmico, as duas últimas tipologias de documentos foram excluídas. Cabe, ainda, ressaltar que, dos (47) quarenta e sete trabalhos que restaram, (6) seis foram excluídos por, na busca, serem capturados duplicados a partir do resumo em inglês e (1) um 
que, além de estar duplicado e capturado por outro idioma, foi publicado duas vezes em periódicos diferentes em anos consecutivos (SEITZ, 2005; 2006). Portanto, triplicado na BRAPCI.

Os textos referidos são: Biblioterapia aplicada com estudantes de biblioteconomia da UFSC: uma vivência terapêutica com histórias. Trabalho de autoria de Carla Sousa e Clarice Fortkamp Caldin, apresentado no Encontro Nacional de Pesquisa em Ciência da Informação (2016); Editorial, n. 14, 2002 do periódico; Encontros Bibli: Revista Eletrônica de Biblioteconomia e Ciência da Informação. Temos ainda, os trabalhos capturados duplicados a partir do resumo em inglês: Bibliotherapy for intern children at the hospital universitary of UFSC: an experience; The therapeutic applicability of literaries texts for children; Bibliotherapy for preschool children: a case study; Bibliotherapy: comparative study on bibliotherapeutic practices in Brazil and in United States; Bibliotherapy: a tool for hospital psychologist proceeding in attending the hospitalized child.

Por fim, o trabalho encontrado triplicado: Bibliotherapy: an experience with patients interned in medical clinica/ Biblioterapia: uma experiência com pacientes internados em clínicas médicas (2006). Consideramos, para a análise, o publicado em 2005, uma vez que entendemos que a publicação primeira é a que confere originalidade ao trabalho. Por essa ótica, temos como corpus de análise o exame de apenas (40) quarenta trabalhos, levantados na data de 24 de janeiro de 2018.

De mão do corpus documental capturado, utilizamo-nos de técnicas de análise, inspiradas no método de análise de conteúdo de Bardin (2009). A partir dela, delineamos a análise do material em três etapas: organização, categorização e inferências, lembrando que temos como recorte da produção os anos de 1975-2017 (A delimitação dessas datas deveu-se por ser a primeira o ano em que se apresenta o primeiro estudo publicado com a temática no Brasil. E 2017, por ser o ano que mantém as publicações mais atualizadas sobre nosso foco temático, já que, apesar de estarmos em 2018, segundo a BRAPCl, no momento da captura dos trabalhos, ainda não se tinha fascículos de periódicos com publicações sobre o ano em questão).

Dessa forma, na primeira etapa, levantou-se o mapeamento cronológico dos estudos, bem como o levantamento dos autores. Com base neste último aspecto, fomos levados ao segundo território de constituição de análise: a Plataforma Lattes. Nela, com foco nos currículos lattes dos autores, estabelecemos as categorias de 
análise, estruturadas a partir dos objetivos específicos do estudo. Por fim, as inferências, quando pontuamos o nosso olhar a partir dos dados levantados e dialogamos com alguns autores, no intuito de ampliar a discussão trazida frente às informações cartografadas, como pode ser observado a seguir.

5 O QUE OS DADOS NOS DIZEM: UM OLHAR SOBRE A PAISAGEM RASTREADA

Começaremos a desenhar nossa paisagem sobre a biblioterapia no Brasil a partir do comportamento da produção do tema em nosso país. Nesse sentido, evidenciamos discussões iniciais sobre o assunto a partir de 1975, sendo a precursora, segundo os dados levantados, Ângela Maria Lima Ratton, com o texto intitulado: Biblioterapia, publicado na Revista da Escola de Biblioteconomia, da Universidade Federal de Minas Gerais (UFMG), estando esta, atualmente, com suas atividades encerradas.

No gráfico que segue, mostraremos o comportamento das produções ao longo dos anos. No entanto, antecipamos que o desenvolvimento do tema não se mostra linear, demonstrando interrupções (seis anos entre 1975 a 1982; catorze entre 1982 a 1997; dois anos entre 1998 a 2001, apresentando, com isso, vinte e dois anos no total de lacuna sem produção) e retomadas (desde de 2001, apresenta uma produção contínua, ressaltando uma lacuna apenas no ano de 2010 , sem nenhuma produção).

GRÁFICO 1 - O comportamento da produção acadêmica em 
biblioterapia ao longo do tempo em periódicos brasileiros em $\mathrm{Cl}$ e Biblioteconomia.

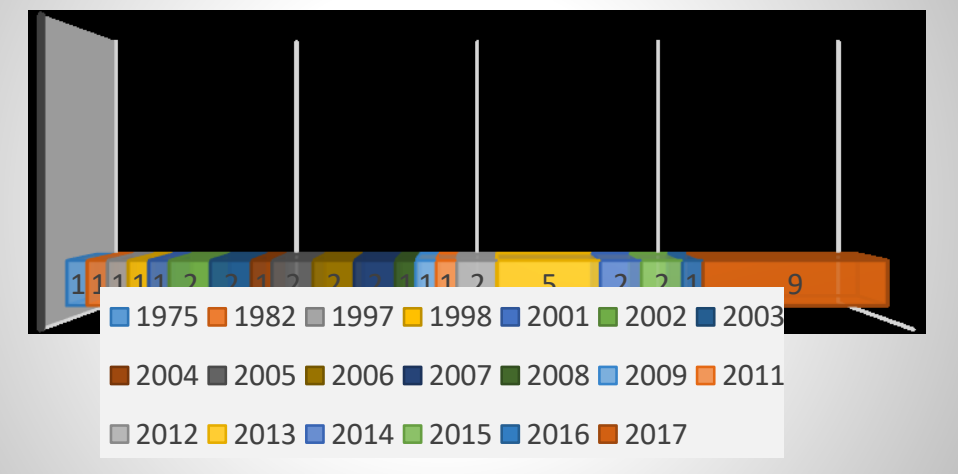

FONTE: Produção para a pesquisa.

Percebemos, pelo gráfico, que, desde a publicação do primeiro escrito até a atualidade, passaram-se quarenta e dois anos e a produção acadêmica publicada em nosso país por meio dos periódicos se limita a quarenta trabalhos. Tiveram destaque os anos de 2013 e 2017 com cinco e nove trabalhos, respectivamente, publicados. Por essa trama de dados, observamos um aumento considerável quanto ao quantitativo de produções no que compete ao tema, uma vez que, em estudos de mesmo sentido, é demonstrado um número inferior quanto a esse aspecto.

A exemplo, diante de um recorte entre os anos 1997-2007, a partir de critérios como buscas na Internet e elaboração de lista de periódicos científicos de acesso aberto, elaborada mediante o endereço eletrônico do Conselho Federal de Biblioteconomia (CFB) e do Portal Periódicos Capes, o estudo de Leite (2010) aponta apenas 15 artigos.

Silva; Salgado (2013), assemelhando-se à nossa investigação, à medida que também tem a BRAPCI como espaço de investigação, identificou 21 artigos. Vale ressaltar que mesmo não tendo como critério a cronologia, os dados demonstrados nos permitem inferir que o estudo pautou-se a partir do recorte delimitado entre os anos de 1998 a 2013. Desse modo, podemos afirmar que nossa proposição é mais ampla que os anteriores, uma vez que cobre cronologicamente um recorte temporal superior a esses, totalizando o estudo de 42 (quarenta e dois anos) de pesquisa no tema foco, em paralelo aos 10 (dez) anos de Leite 
(2010) e 15 (quinze) anos de Silva; Salgado (2013).

Em relação à autoria, no corpus de análise, foram identificados (60) sessenta autores. Desses, o autor em destaque (vermelho) na tabela que segue foi desconsiderado, uma vez que o rastreio foca-se apenas em autores brasileiros e ele tem nacionalidade portuguesa ${ }^{5}$. Nesse sentido, na produção rastreada, a autora que mais se destaca é Clarice Fortkamp Caldin Pesquisadora, Professora da Graduação em Biblioteconomia e da Pós-graduação em Ciência da Informação, da Universidade Federal de Santa Catarina (UFSC), sendo a principal teórica sobre a temática no Brasil. Por essa perspectiva, encontramos 5 (cinco) trabalhos em autoria única dela e outros 5 (cinco), que integra como coautora, representando um percentual de $25 \%$ (vinte e cinco por cento) do total de trabalhos levantados. O destaque para essa autora converge ao apontado por Silva; Salgado (2013, não paginado) quando apontam a autora tanto como a que mais se destaca na produção, quanto como referência para outros pesquisadores sobre o tema.

Além dela, evidenciamos que Eva Maria Seitz e Edna Gomes Pinheiro são outros nomes que se destacam. A primeira com a biblioterapia no ambiente hospitalar; a segunda, com intervenções biblioterapêuticas com idosos. No entanto, além delas, outros nomes figuram, como visto a seguir, no empreendimento de ter a biblioterapia como escopo de pesquisa e atuação.

TABELA 1 - Autoria em publicações periódicas em $(\mathrm{Cl})$ e Biblioteconomia no tema biblioterapia no Brasil.

\begin{tabular}{|c|l|c|l|}
\hline 1 & ALMEIDA, Edson Marques. & 31 & LEITE, Manuela Bravo. \\
\hline 2 & ALVES, Maria Helena Hees. & 32 & LIMA, Daiana de. \\
\hline 3 & ALVES, Marília Amaral Mendes. & 33 & $\begin{array}{l}\text { LUCAS, Elaine Rosangela de } \\
\text { Oliveira. }\end{array}$ \\
\hline 4 & ANDRADE, Lucas Veras de. & 34 & MAGALHAES, Michelle Cristina. \\
\hline 5 & AZEVEDO, Fernando. & 35 & $\begin{array}{l}\text { MARQUEZ, Suely Oliveira } \\
\text { Moraes. }\end{array}$ \\
\hline 6 & $\begin{array}{l}\text { BAHIANA, Neiva Dulce Suzart } \\
\text { Alves. }\end{array}$ & 36 & MELO, Ana Caroline Viana de. \\
\hline 7 & BALBINOTTI, Stheve. & 37 & MOSTAFA, Solange Puntel. \\
\hline 8 & BAPTISTA, Sofia Galvão. & 38 & $\begin{array}{l}\text { NASCIMENTO, Geovana } \\
\text { Mascarenhas do. }\end{array}$ \\
\hline 9 & $\begin{array}{l}\text { BELMINO, Marcus Cézar de } \\
\text { Borba. }\end{array}$ & 39 & PINHEIRO, Edna Gomes. \\
\hline 10 & BENEVENUTTO, Felipe Etelvino. & 40 & PINTO, Virgínia Bentes. \\
\hline 11 & BERNARDINO, Maria Cleide & 41 & RAMOS, Rubem Borges Teixeira. \\
\hline
\end{tabular}

${ }^{5}$ Publica em território nacional em coautoria com pesquisadores brasileiros. 


\begin{tabular}{|c|l|c|l|}
\hline & Rodrigues. & & \\
\hline 12 & BOWMAN, Garry. & 42 & RATTON, Ângela Maria Lima. \\
\hline 13 & BUENO, Silvana Beatriz. & 43 & ROLIM NETO, Modesto Leite. \\
\hline 14 & CALDIN, Clarice Fortkamp. & 44 & $\begin{array}{l}\text { ROSEMBERG, Dulcinea } \\
\text { Sarmento. }\end{array}$ \\
\hline 15 & CALIXTO, Anny Caroliny Leite. & 45 & ROSSI, Luciene. \\
\hline 16 & CASTRO, Rachel Barbosa de. & 46 & ROSSI, Tatiana. \\
\hline 17 & CRUZ, Denise Viuniski da Nova. & 47 & ROSSETTO, Adriana Pereira. \\
\hline 18 & ELLIOTT, Ariluci Goes. & 48 & SANTOS, Andréa Pereira dos. \\
\hline 19 & $\begin{array}{l}\text { FELIPE, André Anderson } \\
\text { Cavalcante. }\end{array}$ & 49 & SANTOS, Maryse Azevedo dos. \\
\hline 20 & FERREIRA, Danielle Thiago. & 50 & SEITZ, Eva Maria. \\
\hline 21 & FONSECA, Karla Hayde Oliveira. & 51 & $\begin{array}{l}\text { SILVA, Diego Maradona Souza } \\
\text { da. }\end{array}$ \\
\hline 22 & GARCIA, Inez Helena. & 52 & SILVA, Juliana Carla Gomes. \\
\hline 23 & GARCIA, Joana Coeli Ribeiro. & 53 & SILVA, Mona Lisa. \\
\hline 24 & GERLIN, Meri Nadia Marques. & 54 & SILVA, Patrícia V. Pinheiro da. \\
\hline 25 & GOMES, Micarla do Nascimento. & 55 & SILVA, Paulo Roberto Freitas da. \\
\hline 26 & GOMES, Jesiel Ferreira. & 56 & SOUSA, Carla. \\
\hline 27 & GONÇALVES, Eliete. & 57 & SOUSA, Thais Caroline Silva. \\
\hline 28 & GUEDES, Mariana Giubertti. & 58 & SOUZA, Marinilva Rodrigues de. \\
\hline 29 & $\begin{array}{l}\text { GRASSELLI, Leticia Aurora de } \\
\text { Almeida. }\end{array}$ & 59 & TREIN, Juliane Marlei. \\
\hline 30 & JERÔNIMO, Viviane. & 60 & $\begin{array}{l}\text { VALENCIA, Maria Cristina } \\
\text { Palhares. }\end{array}$ \\
\hline
\end{tabular}

FONTE: Produção para a pesquisa.

Ainda sobre autoria, a análise contemplou traçar o perfil dos autores. Cabe ressaltar que, dos cinquenta e nove autores levantados, $23,7 \%$ ou 14 (catorze) não foram encontrados na plataforma lattes. Nesse sentido, no que se refere a esse aspecto, apenas 45 (quarenta e cinco) encorpam o estudo, tendo como desenho de paisagem os seguintes perfis: em relação à formação inicial, $67,2 \%$ ou 37 (trinta e sete) têm como graduação o curso de Biblioteconomia, seguido, respectivamente, de $6,8 \%$ ou 4 (quatro) com formação em Psicologia; 3,4\% ou 2 (dois), em Ciência da Informação; $1,7 \%$ ou 1 (um), em Medicina e 1,7\% ou 1 (um), em Comunicação Social.

Quanto ao grau de titulação, tem-se: $5,1 \%$ ou 3 (três) PósDoutores; $27,1 \%$ ou 16 (dezesseis) Doutores; $15,3 \%$ ou 9 (nove) Mestres; $6,8 \%$ ou 4 (quatro) Especialistas e, por fim, 22\% ou 13 (treze) Graduados. Com os dados, percebemos que, com o tempo, o aspecto titulação é aumentado, já que Leite (2010) aponta, em seu estudo, que, na época de sua investigação, nenhum autor possuía Pós-Doutorado ou Doutorado, sendo a maior parte dos autores Mestres.

Outro aspecto que assemelha nossa pesquisa à de Leite 
(2010) é o fato de também caracterizar a atuação profissional dos autores. Dos dados referentes a esse tópico, encontramos, pelo território da plataforma lattes, que a maioria, $32,2 \%$ ou 19 (dezenove) são docentes universitários; $20,3 \%$ ou 12 (doze) são bibliotecários; $11,9 \%$ ou 7 (sete) não possuem vínculo empregatício; $3,4 \%$ ou 2 (dois) são psicólogos; $1,7 \%$ ou 1 (um) é instrutor horista; $1,7 \%$ ou 1 (um) é técnica em enfermagem; $1,7 \%$ ou 1 (um) é professor da educação básica; $1,7 \%$ ou 1 (um) é técnico em arquivo e, por último, $1,7 \%$ ou 1 (um) é técnico em documentação. Nossos achados quanto a isso convergem para Leite (2010), no sentido de demonstrarem a carreira docente e a atividade empírica de bibliotecário, respectivamente, como as atuações que mais se destacam na ocupação dos autores.

$\mathrm{Em}$ relação às instituições de origem dos autores, foram mapeadas 35 (trinta e cinco). Dessas, destacamos a Universidade Federal do Cariri (UFCA), que possui o percentual de $8,1 \%$ ou 3 (três) da vinculação dos autores e a Universidade Federal de Santa Catarina (UFSC), que tem vinculada Clarice Fortkamp Caldin, pesquisadora que, dentre todos os autores como já demonstrado, é a que mais produz(iu) e publica(ou) no espaço estudado sobre o tema, além de ser uma das líderes do primeiro grupo de pesquisa no Brasil sobre biblioterapia, denominado Laboratório de Estudos em Biblioterapia, Bibliotecas Escolares e Leitura ${ }^{6}$.

Sabemos que a pesquisa é um eixo importante para que um tema se desenvolva e se consolide no meio acadêmico. Dos dados aferidos nos territórios estudados, percebemos que apenas 26 (vinte e seis) dos 59 (cinquenta e nove) ${ }^{7}$ autores levantados possuem vínculo com a pesquisa. Desses, 20 (vinte) estão vinculados a 48 (quarenta e oito) grupos de pesquisas, distribuídos em 66 (sessenta e seis) linhas de pesquisas sem vínculo específico com a biblioterapia. As pesquisas destes com o tema aqui refletido, compreende-se a partir de uma perspectiva interdisciplinar. $O$ restante, apenas um total de 6 (seis), estuda temas mais direcionados à biblioterapia, no entanto, sem tê-la como foco exclusivo.

Ainda em relação a esse aspecto, além da UFSC, pela escavação nas bases, observamos que a Universidade Estadual do

\footnotetext{
6 Dados sobre o grupo disponível em: http://dgp.cnpq.br/dgp/espelhogrupo/1872681527139655.

${ }^{7}$ Do total de cinquenta e nove autores, $23,7 \%$ ou 14 (catorze) não foram encontrados na plataforma lattes e $32,2, \%$ ou 19 (dezenove) não estão vinculados com grupos de pesquisa.
} 
Piauí (UESPI) também detém institucionalizada a pesquisa em biblioterapia. Nesta instituição, encontra-se o Grupo de Estudos e Pesquisas em Biblioteconomia e Ciência da Informação (GEPEBIC), que possui, em suas reflexões, a linha de pesquisa: Literatura, leitura e biblioterapia ${ }^{8}$. Nesse sentido, cartografamos apenas dois grupos de pesquisa no Brasil. Nesses, somente o vínculo de seis pesquisadores com linha de estudo no tema. Nisso, pontuamos a temática da biblioterapia como uma linha de investigação em potencial para novos pesquisadores e um campo com muitos rizomas $^{9}$ a serem explorados.

Com os dados analisados até aqui, pode surgir a seguinte ponderação: Se há um número limitado de pesquisadores específicos, como, então, a pesquisa em biblioterapia é desenvolvida? Por nossa cartografia, observamos, a partir do currículo lattes e da relação deles pela autoria dos artigos, que muitos dos trabalhos cartografados são resultantes da orientação monográfica, a partir de trabalhos de conclusão de curso em Biblioteconomia (grande maioria). Sendo outros resultantes do empirismo de projetos de extensão ${ }^{10}$, da iniciativa isolada e autônoma dos autores.

Em relação à produção dos grupos de pesquisa em biblioterapia mencionados, quando relacionamos autoria e vinculação, observamos uma contribuição mínima na produção escavada, totalizando, nesse

8 Dados o sobre grupo disponível em:

http://dgp.cnpq.br/dgp/espelhogrupo/1062236174272128.

${ }^{9}$ Conceito desenvolvido por Gilles Deleuze e Félix Guattari. E no estudo, é entendido como uma forma de pensamento não linear, compreendendo desta forma, uma multiplicidade de conexões sem privilegiar um ou outro conhecimento. Ver: DELEUZE, Gilles \& GUATTARI, Félix. Mil Platôs: capitalismo e esquizofrenia. Rio de Janeiro: Ed. 34. 2000.

${ }^{10}$ No estudo foram levantados 14 (catorze) projetos extensionistas, a citar: Doutores da Leitura; Biblioterapia na ala pediátrica do HU; Biblioterapia com crianças portadoras de câncer: a leitura como atividade lúdica; Projeto de Extensão com a parceria do HC para a atividade de Biblioterapia com os pacientes do Hospital; Biblioterapia e terceira idade: a função terapêutica da leitura em idosos asilados na cidade de Cuité - PB; Projeto Reviver: a Biblioterapia como coadjuvante no tratmento de crianças portadoras de câncer; Projeto RENASCER: biblioterapia para idosos; O uso da biblioterapia como coadjuvante no tratamento de crianças portadora de câncer do hospital Albert Sabin em Fortaleza-Ce; Biblioterapia para velhos jovens/idosos: envelhercer é viver e nada mais; Projeto Bem-Te-Vi; A biblioterapia como a arte de encantar criança com câncer; Projeto Renascer: a biblioterapia como um novo acontecer na qualidade de vida do idoso; Biblioterapia no Hospital Albert Sabin; Práticas Leitoras da Biblioterapia no Abrigo SOS-Criança; Biblioterapia como Coadjuvante no Tratamento do Câncer Infantil no Hospital Infantil Albert Sabin; Sala de Leitura Salim Miguel. 
sentido, $27,5 \%$ ou 11 (onze) dos artigos explorados no estudo. Um aspecto que pode contribuir para a baixa produção destes é o fato de, neles, a biblioterapia não ser tema exclusivo e foco das discussões, uma vez que os espelhos dos grupos no Diretório de Grupos de Pesquisas, do Conselho Nacional de Pesquisa (CNPq), demonstramnos com enfoques diversos, estando o tema da biblioterapia ligado ao eixo central de tema dos grupos. Sendo este na UFSC o incentivo à leitura e à revitalização de bibliotecas escolares e na UESPI, o processo de produção, organização e disseminação do conhecimento científico, tecnológico e sua dinâmica nos contextos sociais políticos, econômicos e culturais.

Cabe, ainda, apontar o número limitado de pesquisadores ou mesmo o ano de certificação do grupos (início de atividades e vigência), variando entre 2004 (Laboratório de Estudos em Biblioterapia, Bibliotecas Escolares e Leitura) e 2015 (GEPEBIC); assim como as inserções no grupo dos pesquisadores, variando as datas entre os anos de 2004, 2015, 2016 e 2017.

Outro aspecto relevante em nossa cartografia é a distribuição geográfica dos estudos. Antes, porém, cabe salientar que encontramos autores em todas as regiões brasileiras. Observamos que, entre as regiões, a que mais se destaca, com o maior número de autores, é a região nordeste, com $32,2 \%$ ou 19 (dezenove) autores, seguida das regiões sul, com 18,6\% ou 11 (onze) autores; sudeste, com $15,3 \%$ ou 9 (nove) autores; centro-oeste, com $8,5 \%$ ou 5 (cinco) autores e, por fim, a região norte, com $1,7 \%$ ou 1 (um) autor.

É interessante pontuar que nem sempre o lugar de produção de conhecimento sobre a biblioterapia é o mesmo de publicação. Ao compararmos os dados da produção em relação à de publicação, evidenciamos que este aspecto diverge, sendo a região sul a que lidera entre as regiões. Converge, assim, para os estudos de Leite (2010), dando destaque para os periódicos: Revista ACB: Biblioteconomia em Santa Catarina e Encontros Bibli: Revista Eletrônica de Biblioteconomia e Ciência da Informação. Desse modo, como forma de possibilitar a noção da produção em biblioterapia no Brasil, nos periódicos, e sistematizar as ideias rastreadas, segue um quadro representativo que detalha o periódico e a quantidade de trabalhos inseridos em cada um:

TABELA 2 - Produção acadêmica em Biblioterapia nos periódicos em (Cl) e Biblioteconomia. 
Periódicos em Biblioteconomia e Ciência da Informação

\begin{tabular}{|c|c|c|}
\hline 1 & Revista ACB: Biblioteconomia em Santa Catarina. & 9 \\
\hline 2 & $\begin{array}{l}\text { Encontros Bibli: Revista Eletrônica de Biblioteconomia e } \\
\text { Ciência da Informação. }\end{array}$ & 5 \\
\hline 3 & Biblionline. & 4 \\
\hline 4 & Revista Brasileira de Biblioteconomia e Documentação. & 4 \\
\hline 5 & $\begin{array}{l}\text { Revista Digital de Biblioteconomia e Ciência da } \\
\text { Informação. }\end{array}$ & 3 \\
\hline 6 & ETD - Educação Temática Digital. & 2 \\
\hline 7 & Informação \& Informação. & 2 \\
\hline 8 & Múltiplos Olhares em Ciência da Informação. & 1 \\
\hline 9 & Revista Conhecimento em Ação. & 1 \\
\hline 10 & Brazilian Journal of Information Studies: Research Trends. & 1 \\
\hline 11 & Perspectivas em Ciência da Informação. & 1 \\
\hline 12 & DataGramaZero ${ }^{11}$. & 1 \\
\hline 13 & Transinformação. & 1 \\
\hline 14 & Informação \& Sociedade: Estudos. & 1 \\
\hline 15 & Reciis - Rev. Eletron. Comun. Inf. Inov. Saúde. & 1 \\
\hline 16 & $\begin{array}{l}\text { Biblos: Revista do Instituto de Ciências Humanas e da } \\
\text { Informação. }\end{array}$ & 1 \\
\hline 17 & Revista da Escola de Biblioteconomia da UFMG ${ }^{12}$ & 1 \\
\hline 18 & Informação@Profissões. & 1 \\
\hline & Total & 40 \\
\hline
\end{tabular}

FONTE: Elaboração dos autores para a Pesquisa.

Diferente da pesquisa de Leite (2010) e Silva; Salgado (2013), que apontaram 10 (dez) e 9 (nove) periódicos, respectivamente, com publicações sobre o tema, os dados de nossa exploração cartográfica apontam 18 (dezoito). $\mathrm{O}$ aumento dos periódicos publicando sobre biblioterapia pode ser justificado pela proliferação de periódicos atrelados à pós-graduação crescente na área de $\mathrm{Cl}$ em nosso país e do aumento natural de periódicos póstumos aos estudos demonstrados. Que tem como foco e escopo além de pontos tradicionais da $\mathrm{Cl}$, como os processos de produção, organização e disseminação, tem na mediação da informação, o elo que encaixa a biblioterapia como escopo também passível de ser apropriado ao conjunto de investigações em Cl. Ressalta-se, ainda, - caráter interdisciplinar com diálogo com outras áreas de conhecimento. A seguir, as referências cartografadas no estudo.

1. ALMEIDA, Edson Marques; GOMES, Micarla do Nascimento; SILVA, Diego Maradona Souza da; SILVA, Mona Lisa. Biblioterapia: o bibliotecário

\footnotetext{
${ }^{11}$ Periódico com atividades encerradas a partir de 2015.

12 Periódico com nomenclatura substituída a partir de 1996 para Perspectivas em Ciência da Informação (PCl).
} 
como agente integrador e socializador da informação. Múltiplos Olhares em Ciência da Informação, Belo Horizonte, v. 3, n. 2, 2013.

2. ALVES, Maria Helena Hees. A aplicação da biblioterapia no processo de reintegração social. Revista Brasileira de Biblioteconomia e Documentação, São Paulo, v. 15, n. 1/2, p. 54-61, 1982.

3. BALBINOTTI, Stheve. Páginas ansiosas: uma viagem pelo oceano da ansiedade até desembarcar na ilha da biblioterapia. Biblionline, João Pessoa, v. 13, n. 1, p. 43-50, jan./mar. 2017.

4. BAHIANA, Neiva Dulce Suzart Alves. A utilização da biblioterapia no ensino superior como apoio para a auto-ajuda: implementação de projeto junto aos educandos em fase de processo monográfico. Revista Digital de Biblioteconomia \& Ciência da Informação, Campinas, v. 7, n. 1, p. 65-79, 2009.

5. BERNARDINO, Maria Cleide Rodrigues; ELLIOTT, Ariluci Goes; ROLIM NETO, Modesto Leite. Biblioterapia com Crianças com Câncer. Informação \& Informação, Londrina, v. 17, n. 3, p. 198-210, set./ dez., 2012.

6. BOWMAN, Garry. Biblioterapia: uma técnica para Aconselhamento Cegos. Revista Brasileira de Biblioteconomia e Documentação, São Paulo, v. 26-28, n. 1, p. 74-83, 1997.

7. BUENO, Silvana Beatriz; CALDIN, Clarice Fortkamp. A aplicação da biblioterapia em crianças. Revista ACB: Biblioteconomia em Santa Catarina, Florianópolis, v. 7, n. 2, p. 157-170, 2002.

8. CALDIN, Clarice Fortkamp. A Teoria Merleau-Pontyana da linguagem e a biblioterapia. Revista Digital de Biblioteconomia e Ciência da Informação, Campinas, v. 8, n. 2, p. 23-40, jan./jun. 2011.

9. A aplicabilidade terapêutica de textos literários para crianças.

Encontros Bibli: Revista Eletrônica de Biblioteconomia e Ciência da Informação, Florianópolis, v. 9, n. 18, p. 72-89, 2004.

10. Biblioterapia para crianças internadas no hospital universitário da UFSC: uma experiência. Encontros Bibli: Revista Eletrônica de Biblioteconomia e Ciência da Informação, Florianópolis, v. 7, n. 14, p. 38-54, 2002.

11. . Biblioterapia para a classe matutina de aceleração da Escola de Educação Básica Dom Jaime de Barros Câmara: relato de experiência. Revista ACB: Biblioteconomia em Santa Catarina, Florianópolis, v. 8, n. 1, p. 10-17, 2003.

12. A leitura como função terapêutica: biblioterapia. Encontros Bibli: Revista Eletrônica de Biblioteconomia e Ciência da Informação, Florianópolis, v. 6, n. 12, p. 32-44, 2001.

13. CALIXTO, Anny Caroliny Leite; BELMINO, Marcus Cézar de Borba. BIBLIOTERAPIA: uma ferramenta para atuação do psicólogo Hospitalar no atendimento à criança hospitalizada. Biblionline, João Pessoa, v. 9, n. 2, 
p. 19-33, 2013.

14. CASTRO, Rachel Barbosa de; PINHEIRO, Edna Gomes. Biblioterapia para idosos: o que fica e o que significa. Biblionline, João Pessoa, v. 1, n. 2, p. 1-13, 2005.

15. FELIPE, André Anderson Cavalcante; GOMES, Jesiel Ferreira. A parceria entre Ciência da Informação e responsabilidade social universitária para fins de inclusão social. Rev. digit. bibliotecon. cienc. inf., Campinas, v. 12, n. 1, p. 147-163, jan/abr., 2014.

16. FERREIRA, Danielle Thiago. Biblioterapia: uma prática para o desenvolvimento pessoal. ETD - Educação Temática Digital, Campinas, v. 4, n. 2, p. 35-47, 2003.

17. FONSECA, Karla Hayde Oliveira. A leitura dos clássicos, uma possibilidade biblioterapêutica: por um viver melhor. Revista ACB: Biblioteconomia em Santa Catarina, Florianópolis, v. 19, n. 1, p. 6-12, jan./jun., 2014.

18. FONSECA, Karla Hayde Oliveira.; AZEVEDO, Fernando. Biblioterapia: relato de uma experiência no lar de idosos em Braga - Portugal. Revista ACB: Biblioteconomia em Santa Catarina, Florianópolis, v. 21, n. 2, p. 381-389, abr./ jul., 2016.

19. GARCIA, Inez Helena. Biblioterapia: percepções dos discentes dos cursos de Biblioteconomia das universidades federal e estadual de Santa Catarina. Encontros Bibli: Revista Eletrônica de Biblioteconomia e Ciência da Informação, Florianópolis, v. 20, n. 43, 2015. (Resumo de Dissertação).

20. GUEDES, Mariana Giubertti; BAPTISTA, Sofia Galvão. Biblioterapia na Ciência da Informação: Comunicação e Mediação. Encontros Bibli: revista eletrônica de biblioteconomia e ciência da informação, Florianópolis, v. 18, n. 36, p. 231-253, jan./abr., 2013.

21. GRASSELLI, Leticia Aurora de Almeida; GERLIN, Meri Nadia Marques. Aproximações entre a biblioterapia e o teatro clown: uma reflexão sobre a atuação do bibliotecário no ambiente hospitalar. Revista Conhecimento em Ação, Rio de Janeiro, v. 2, n. 1, p. 78-92, jan./jun. 2017.

22. JERÔNIMO, Viviane; ROSSETTO, Adriana Pereira; SILVA, Paulo Roberto Freitas da; GONÇALVES, Eliete; TREIN, Juliane Marlei. Biblioterapia na melhor idade. Revista ACB: Biblioteconomia em Santa Catarina, Florianópolis, v. 17, n. 2, p. 460-471, 2012.

23. LEITE, Manuela Bravo; CALDIN, Clarice Fortkamp. Programas de aplicação da biblioterapia no Reino Unido. Brazilian Journal of Information Studies: Research Trends. Marília, v. 11, n. 3, p. 53-65, 2017.

24. LIMA, Daiana de; CALDIN, Clarice Fortkamp. Aplicação da biblioterapia na Escola Básica Municipal Luiz Cândido da Luz. Revista ACB: Biblioteconomia em Santa Catarina, Florianópolis, v. 18, n. 1, p. 599-622, jan./jun., 2013. 
25. LUCAS, Elaine Rosangela de Oliveira; CALDIN, Clarice Fortkamp; SILVA, Patrícia V. Pinheiro da. Biblioterapia para crianças em idade préescolar: estudo de caso. Perspectivas em Ciência da Informação, Belo Horizonte, v. 11, n. 3, p. 398-415, 2006.

26. MOSTAFA, Solange Puntel; CRUZ, Denise Viuniski da Nova; BENEVENUTTO, Felipe Etelvino. Fenomenologia versus Filosofia da Diferença: a Biblioterapia em questão. DataGramaZero, Brasília, v. 14, n. 6, p. A03, 2013.

27. NASCIMENTO, Geovana Mascarenhas do; ROSEMBERG, Dulcinea Sarmento. A biblioterapia no tratamento de enfermos hospitalizados. Informação \& Informação, Londrina, v. 12, n. 1, p. 1-13, 2007.

28. PINTO, Virgínia Bentes. A biblioterapia como campo de atuação para o bibliotecário. Transinformação, Campinas, v. 17, n. 1, p. 31-43, 2005.

29. PINHEIRO, Edna Gomes. Biblioterapia para o idoso Projeto Renascer: um relato de experiência. Informação \& Sociedade: Estudos, Paraíba, v. 8, n. 1, p. 155-163, 1998.

30. RATTON, Ângela Maria Lima. Biblioterapia. Revista da Escola de Biblioteconomia da UFMG, Belo Horizonte, v. 4, n. 2, p. 198-214, 1975.

31.ROSSI, Tatiana; ROSSI, Luciene; SOUZA, Marinilva Rodrigues de. Aplicação da biblioterapia em idosos da Sociedade Espírita Obreiros da Vida Eterna (SEOVE). Revista ACB: Biblioteconomia em Santa Catarina, Florianópolis, v. 12, n. 2, p. 322-340, 2007.

32. SILVA, Juliana Carla Gomes; GARCIA, Joana Coeli Ribeiro. O projeto de lei $n^{\circ}$ 4186/2012: em cena a atuação da biblioterapia. Biblionline, João Pessoa, v. 13, n. 1, p. 173, jan./mar. 2017. (Resumo de Monografia).

33. SANTOS, Andréa Pereira dos; RAMOS, Rubem Borges Teixeira; SOUSA, Thais Caroline Silva. Biblioterapia: estudo comparativo das práticas biblioterápicas brasileiras e norte-americanas. Reciis - Rev. Eletron. Comun. Inf. Inov. Saúde, Rio de Janeiro, v. 11, n. 2, p. 1-15, abr./jun., 2017.

34. SEITZ, Eva Maria. A biblioterapia na humanização da assistência hospitalar do hospital universitário da Universidade Federal de Santa Catarina. ETD - Educação Temática Digital, Campinas, v. 9, n. 2, p. 145-169, 2008.

35.

Biblioterapia: uma experiência com pacientes internados em clínicas médicas. Revista ACB: Biblioteconomia em Santa Catarina, Florianópolis, v. 11, n. 1, p. 155-170, 2006.

36. VALENCIA, Maria Cristina Palhares; MAGALHAES, Michelle Cristina. Biblioterapia: síntese das modalidades terapêuticas utilizadas pelo profissional. Biblos: Revista do Instituto de Ciências Humanas e da Informação, v. 29, n. 1, p. 5-27, 2015.

37. ALVES, Marília Amaral Mendes. Biblioterapia: uma experiência inovadora no curso de biblioteconomia da UNIRIO. Revista Brasileira de 
Biblioteconomia e Documentação, São Paulo, v. 13, n. esp., p. 20652077, CBBD 2017.

38. SOUSA, Carla; CALDIN, Clarice Fortkamp. Contos de fadas também é coisa de gente grande: aplicabilidade terapêutica de histórias infantis para adultos. Revista ACB: Biblioteconomia em Santa Catarina, Florianópolis, v. 22, n. 3, p. 548-563, ago./nov., 2017.

39. ANDRADE, Lucas Veras de; MELO, Ana Caroline Viana de. Um diálogo entre a vida real e a literatura infanto-juvenil: uma experiência de leitura na perspectiva da produção de sentidos. Inf. Prof., Londrina, v. 6, n. 1, p. $162-173$, jan./jun. 2017.

40. SANTOS, Maryse Azevedo dos; MARQUEZ, Suely Oliveira Moraes. Biblioterapia: a contribuição da biblioterapia no tratamento de pacientes internados em unidades hospitalares. Revista Brasileira de Biblioteconomia e Documentação, São Paulo, v. 13, n. esp., p. 15881608, CBBD, 2017.

\section{MAPA ELABORADO: A BIBLIOTERAPIA É UM CONTORNO EM CURSO!}

Em nosso exercício cartográfico, centramo-nos no mapeamento de pesquisadores e pesquisas em biblioterapia por meio de periódicos. No entanto, dois aspectos, apesar de não intencionados como objetivos no estudo, são relevantes e merecem que os apontemos, pois são fundamentais na incursão sob as trilhas em que se desenvolvem as pesquisas e práticas em biblioterapia, que são: os aspectos teóricos e metodológicos.

Quanto ao primeiro, observamos, a partir dos artigos levantados, que o viés epistemológico em que a biblioterapia é pautada se estabelece sob três enfoques: o primeiro, pela perspectiva da fenomenologia mediante a teoria de Maurice Merleau-Ponty (filosofia da linguagem), seguida pelas proposições de Gilles Deleuze e Félix Guattari (filosofia da diferença) e Psicanálise.

Já no que compete aos aspectos metodológicos, a noção prática enquanto programa de intervenção se demonstra mais esclarecida do que quanto ao seu delineamento. Frente a isso, percebemos protocolos como: elaboração de grafismos, rodas de conversas, uso de atividades lúdicas (teatro, fantoches, contação de histórias, etc.), entre outras. Já quando transposta para o desenvolvimento enquanto pesquisa, inferimos uma ausência refletida quanto a eles, merecendo reflexões mais profundas e um direcionamento a uma abordagem que se adapte às pretensões do objeto da biblioterapia. 
Inclusive, talvez, seja esse o aspecto mais frágil em nossas observações (a falta de clareza quanto ao objeto de estudo da biblioterapia e objetivos mais claros enquanto programa de intervenção), uma vez que é comum encontrarmos, nos próprios estudos, discursos que afirmam que, pela ausência de uma formação específica em biblioterapia, a atividade é desenvolvida pela forma como é compreendida pelo profissional que a desenvolve.

Ainda em relação ao aspecto teórico, reiteramos a fala de Silva (2005, p. 64): "A Biblioterapia [...] [não é] objeto de apreciação ou exame que possa ser examinado [ainda] em livrarias". Antes de refletirmos essa ponderação, já antecipamos a importância dos periódicos nesse sentido, pois são eles que, ao longo da cronologia apontada, vêm disseminando informações sobre o tema, constituindo, dessa forma, o principal território de divulgação científica na área.

Apesar disso, não se constituem como únicos, mencionando também, dessa forma, encontros acadêmicos (com publicações mais tímidas e de acesso restrito aos participantes) e a publicação de uma escassa bibliografia. Em nossa escavação na plataforma lattes, encontramos, a partir do currículo dos autores, títulos ainda "(des)"conhecidos para o público da pesquisa e prática sobre a temática (não há citações deles em algum dos trabalhos encontrados). Apresentando-se, dessa maneira, como arcabouços teóricos para a reflexão sobre o tema, pois além dos livros (principais referências citadas nos artigos), como: Biblioterapia, de autoria de Marc-Alain Ouaknin, quando se pensa em nível internacional e Biblioterapia: um cuidado com o ser, de autoria de Clarice Fortkamp Cladin; Biblioterapia, de Marilia M. Guedes Pereira e Biblioterapia: uma experiência com pacientes internados em clínica médica, de Eva Maria Seitz. Numa perspectiva de produção nacional, podemos, agora, contar com essas produções descortinadas pelos currículos.

Nesse sentido, temos, numa perspectiva interdisciplinar: Saúde mental Coletiva: clínicas e vulnerabilidades, obra de (2012), organizada por Modesto Leite Rolim Neto e mais quatro pesquisadores, a qual possui dois capítulos: $\mathrm{O}$ uso da biblioterapia em auxílio aos pacientes de Alzheimer e Biblioterapia aplicada em adolescentes com depressão. Temos, ainda, Vivências em Biblioterapia: práticas de cuidado através da literatura (2014), de Cristiana Seixas. Por fim, a obra A biblioterapia na realidade bibliotecária no Brasil: a mediação da informação, publicado em 2016, fruto da dissertação de mesma nomenclatura, defendida no Programa de Pós-Graduação em Ciência da Informação, na Universidade de Brasília, por Mariana Giubertti Guedes. 
Em relação ao dados que se referem a nossa cartografia, podemos afirmar que, pelo apresentado nos trabalhos, temos uma grande repetição de ideias, dando destaque para o conceito, os princípios da técnica biblioterapêutica e as diversas tipologias de aplicação. A maioria dos trabalhos constituem-se em pesquisas teóricas, demonstrando uma lacuna quanto a trabalhos empirícos, abrindo, assim, a necessidade de realização de pesquisas com esse enfoque.

Apesar de um número considerável de pesquisadores, o levantamento demonstra que a pesquisa em biblioterapia ainda se apresenta tímida quando comparada a outras áreas dentro do contexto da Biblioteconomia e da Ciência da Informação. No entanto, não se percebe uma produção que se mantém inerte. Apesar de algumas lacunas em determinados períodos, existe um crescimento constante nas publicações ao longo dos anos. Esse aspecto nos faz crer que, pela maioria dos pesquisadores aqui demonstrados se encontrarem vinculados ao ensino superior e na institucionalização do tema em grupos de pesquisas, a comunidade acadêmica já despertou para a temática e encontra-se no trabalho de desenvolvimeto dessa linha de estudo dentro do contexto da Biblioteconomia e da Cl.

Muitos são os temas, públicos e espaços para o desenvolvimento da biblioterapia. Por essa ótica, temos aspectos de ordem emocionais a sociais. Como públicos, temos do infantil ao longevo e espaços que vão da creche ao asilo, o que torna a temática da biblioterapia bastante relevante, já que se configura como um serviço de informação, uma ferramenta relevante para o auxílio das pessoas, de forma a trabalhar seus problemas com intuito de mudanças comportamentais; podendo, ainda, ser aliada, inclusive, ao tratamento tradicional de doenças como coadjuvante em enfermidades diversas.

Dessa forma, a biblioterapia deve ser um campo de estudo mais investigado, assim como uma prática que deve ser reconhecida no Brasil, especialmente quando se remete como um novo escopo de atuação do bibliotecário, já que é ele o profissional com formação específica em mediar informação e prestar serviços de orientação a leitores. No entanto, cabe apontar para a complementação da sua formação com estudos, formações em áreas que abranjam a subjetividade, a produção dela e desenvolvimento humano, aspectos vitais em processos biblioterapêuticos.

Finalizamos chamando atenção para que novas cartografias sejam elaboradas, principalmente ao que se refere a estudos 
empíricos da atividade bibliotecária frente à biblioterapia, pois observamos que estudos sobre essa perspectiva demonstram-se em menor quantidade se comparados com estudos teóricos. Defende-se, ainda, a necessidade da produção de pesquisas voltadas ao enfoque da formação do bibliotecário para a atividade da biblioterapia enquanto área profissional.

Recebido em: 25 mar. 2018 Aceito em: 13 fev. 2019.

\section{REFERÊNCIAS}

ANDRADE, Lucas Veras de; VIANA, Ana Caroline Viana de Melo. Um diálogo entre a vida real e a literatura infantojuvenil: uma experiência de leitura na perspectiva da produção de sentidos. Inf. Prof., Londrina, v. 6, n. $1, \quad$ p. $162-173$, jan./jun. $2017 . \quad$ Disponível em:< http://www.uel.br/revistas/uel/index.php/infoprof/article/view/27382/22362>.

Acesso em: 25 jan., 2018.

ANDRADE, Lucas Veras de. Cartografia de um devir: o movimento de tornar-se bibliotecário aplicador de biblioterapia. Biblionline, João Pessoa, v. $14, \quad$ n. 1 , p. 128-144, 2018. Disponível em:< http://www.periodicos.ufpb.br/ojs/index.php/biblio/article/view/39575/20682>. Acesso em: 12 set. 2018.

ALVES, Maria Helena Hees, A aplicação da Biblioterapia no processo de reintegração social. Revista Brasileira de Biblioteconomia e Documentação, São Paulo, v. 15, n. 1/2, p. 54-61, jan./jun. 1982.

AMORIM NETO, Miguel Romeu; LIMA, Marcia Heloisa Tavares de Figueiredo. O domínio de organização do conhecimento na base BRAPCl: uma análise estatística. Investigación Bibliotecológica, México, v. 30, n. 70, p. 83-104, set./dez., 2016.

BARDIN, Laurence. Análise de Conteúdo. Lisboa, Portugal; Edições 70, LDA, 2009.

CALDIN, Clarice Fortkamp. A leitura como função terapêutica: biblioterapia. Encontros Bibli: Revista Eletrônica de Biblioteconomia e Ciência da Informação, Florianópolis, n. 12, dez. 2001.

. Biblioterapia para crianças internadas no Hospital Universitário da UFSC: uma experiência. Enc. Bibli: R. Eletr. Bibliotecon. Ci. Inf., Florianópolis, Brasil, n. 14, p. 38-54, 2002.

Biblioterapia para a classe matutina de aceleração da escola de educação básica Dom Jaime de Barros Câmara: relato de experiência. Rev. ACB: Biblioteconomia em Santa Catarina, Florianópolis, v. 8/9, p. 10-17, 2003.

Biblioterapia: um cuidado com o ser. São Paulo: Porto de Idéias, 
2010.

CUNHA, Murilo Bastos da. Para saber mais: fontes de informação em ciência e tecnologia. Brasilia: Brinquet de Lemos, 2001.

FOUCAULT, Michel. Arqueologia das ciências e história dos sistemas de pensamento. São Paulo: Forense, 2000.

FREITAS, Juliana Lazzarotto; NASCIMENTO, Bruna Silva do; BUFREM, Leilah Santiago. A organização do conhecimento na dinâmica da pesquisa em artigos da literatura científica da Brapci. Transinformação, Campinas, v. 26, n. 3, p. 295-303, dez. 2014.

GERHARDT, Tatiana Engel; SILVEIRA, Denise Tolfo. Métodos de pesquisa. Porto Alegre: Editora da UFRGS, 2009.

LEITE, Ana Cláudia de Oliveira. Biblioteconomia e biblioterapia: possibilidades de atuação. Revistas de Educação, São Carlos, v. XII, n. 14, p. 23-37, 2009.

Biblioterapia e Biblioterapia: análise da produção científica brasileira. Multiciência, São Carlos, v. 10, p. 24-35, 2010.

MENDONÇA, Maria Alves de. Temáticas biblioteconomia e ciência da informação no Brasil: enfoque nos periódicos científicos eletrônicos. Encontros Biblos: revista eletrônica de biblioteconomia e ciência da informação. Florianópolis, v. 21, n. 46, p. 81-103. maio/agos., 2016.

MULLER, Suzana Pinheiro Machado. Periódico Científico. In: CAMPELLO, Bernadete Santos; CENDÓN, Beatriz Valadares; KREMER, Jeannette Marguerite (Orgs). Fontes de informação para pesquisadores e profissionais. Belo Horizonte: Ed. UFMG, 2000. p. 73-96.

NÓBREGA-THERRIEN, Sílvia Maria; THERRIEN, Jacques. Trabalhos Científicos e Estado da Questão: reflexão teórico-metodológicas. Estudos em Avaliação Educacional, São Paulo, v. 15, n. 30, p. 5-16, jul.-dez./2004.

OHIRA, Maria Lourdes Blatt; SOMBRIO, Márcia Luiza Lonzetti Nunes; PRADO, Noêmia Schoffen. Periódicos brasileiros especializados em biblioteconomia e ciência da informação: evolução. Encontros Bibli: revista eletrônica de biblioteconomia e ciência da informação, Florianópolis, v. 5, n. 10, p. 26-40, jan. 2000.

ORSINI, Maria Stella. O uso da literatura para fins terapêuticos: biblioterapia. Comunicações e Artes, São Paulo, n. 11, p. 139-149, 1982.

OUAKNIN, Marc-Alain. Biblioterapia. Tradução de Nicolás Niymi Campanário. São Paulo: Loyola, 1996.

PEREIRA, Marília M. Guedes. Biblioterapia: proposta de um programa de leitura para portadores de deficiência visual em Bibliotecas Públicas. João Pessoa: Editora Universitária, 1996.

PINTO, Virginia Bentes. A biblioterapia como campo de atuação para o bibliotecário. 
Transinformação, Campinas, v. 17, n. 1, p. 31-43, 2005.

SEITZ, Eva Maria. Biblioterapia: uma experiência com pacientes internados em clínica médica. ETD - Educação Temática Digital, Campinas, v. 7, n. 1, p. 87-102, dez. 2005.

SEITZ, Eva Maria. Biblioterapia: uma experiência com pacientes internados em clínicas médicas. Revista ACB: Biblioteconomia em Santa Catarina, Florianópolis, v. 11, n. 1, p. 155-170, 2006.

SILVA, Alexandre Magno da. Características da produção documental sobre biblioterapia no Brasil. 2005. 122f. Dissertação (Mestrado em Psicologia) - Universidade Federal de Santa Catarina, Centro de Filosofia e Ciências Humanas, Programa de Pós-Graduação em Psicologia, Florianópolis, 2005.

SILVA, Taize Araújo da; SALGADO, Porcina Formiga dos Santos. Um olhar voltado para produção científica brasileira sobre Biblioterapia nos periódicos eletrônicos de acesso livre da área de Ciência da Informação. In: XXV Congresso Brasileiro de Biblioteconomia, Documento e Ciência da Informação, 2013, Florianópolis, Anais... Florianopólis: [s.n], 2013. Disponível em: $<$ https://portal.febab.org.br/anais/article/view/1447>. Acesso em: 22 mar. 2018.

SOUZA, Tirza Egito Rocha; ALBUQUERQUE, Maria Elizabeth B.C. de. Periódicos científicos em biblioteconomia e ciência da informação: Consultas dos alunos concluintes do curso de biblioteconomia. Biblionline. Paraíba, v. 1, n. 2, [não paginado], 2005.

SOUZA, Kellcia Rezende; KERBAUY, Kellcia Rezende. Abordagem quantiqualitativa: superação da dicotomia quantitativa-qualitativa na pesquisa em educação. Educação e Filosofia, Uberlância, v. 31, n. 61, p. 1-19, 2017.

VALENCIA, Maria Cristina Palhares; MAGALHAES, Michelle Cristina. Biblioterapia: síntese das modalidades terapêuticas utilizadas pelo profissional. Biblos: Revista do Instituto de Ciências Humanas e da Informação, São Paulo, v. 29, n. 1, p. 5-27, 2015.

VOSGERAU, Dilmeire Sant'Anna Ramos; ORLANDO, Evelyn de Almeida; MEYER, Patricia. Produtivismo acadêmico e suas repercussões no desenvolvimento profissional de professores universitários. Educ. Soc., Campinas, v. 38, n. 138, p. 231-247, jan.-mar., 2017. 